\section{Publicar nuestra investigación: ¿qué nos detiene?}

\section{To publish our research: what is stopping us?}

\section{Sr. Editor:}

Con el correr de los años la investigación en el ámbito salud ha aumentado su importancia, adquiriendo un rol cada vez más protagónico. Este fenómeno no sólo se debe al aumento en la toma de decisiones con fundamento en la Medicina Basada en Evidencia, sino también por su significativa función en la generación de conocimientos, propiciando el aprendizaje durante la etapa de formación médica ${ }^{1}$. Ello se ha visto reflejado en la incorporación, en las mallas curriculares de las Facultades de Medicina, de principios metodológicos fundamentales para la investigación.

Si bien es importante tener una buena formación metodológica para llevar a cabo una investigación exitosa, también es de una relevancia incluso mayor, tener la iniciativa de llevarla a publicación. Toda investigación tiene por fin ser publicada ${ }^{2}$, o al menos esa debiera ser la meta, pues corresponde a la semántica misma de lo que significa hacer ciencia, es decir, generar conocimientos nuevos y transmitirlos.

La contribución al conocimiento sólo se logra mediante la comunicación y la difusión de la investigación ${ }^{3}$. Sin embargo, esta acepción muchas veces no es comprendida, principalmente por estudiantes de pregrado que recién están incursionando en la investigación; aquello se ve reflejado en que muchos de los trabajos que son presentados en formato "Resumen" en diferentes reuniones científicas, quedan estancados en este paso, descartando su opción a ser publicados.

Este tipo de acontecimientos se ha comprobado en diferentes publicaciones. Por ejemplo, una investigación chilena determinó que sólo 125 $(31,9 \%)$ de un total de 392 resúmenes presentados en Congresos Chilenos de Gastroenterología durante el período 1998-2002 estaban publicados o en vías de hacerlo ${ }^{4}$; otras investigaciones peruanas indican que este número es aún menor, habiendo sido publicados sólo 52 (9,8\%) de 532 resúmenes presentados en Congresos Científicos de Estudiantes de Medicina de Perú durante el período 2002$2009^{5}$. Esta gran fuga o pérdida de conocimiento científico ejemplifica el gran problema que se genera, no sólo porque no se están cumpliendo los objetivos de investigar sino también porque empobrece y disminuye el conocimiento intelectual de un país, pudiendo afectar también a su desarrollo.

Adicionalmente, también se tienen dificultades al momento de publicar, lo que corresponde a otro gran problema sobre todo para los estudiantes de pregrado: ¿Cómo publico? Este inconveniente genera el primer gran obstáculo, y muchas veces el último, para los recién incursionados en esta área. Gran parte de las veces es difícilmente flanqueado debido principalmente a la falta de conocimientos, la frustración que generan sus dificultades y la carencia de apoyo.

Si bien muchas Facultades de Medicina han transformado sus programas de formación ad hoc para la entrega de aspectos metodológicos de investigación, aún falta un gran punto, que corresponde a cómo llevar una investigación a su publicación en una revista, ojalá de alto impacto, y cómo seleccionar dicha revista. Estas carencias se ven comúnmente reflejadas entre los estudiantes de pregrado quienes, por lo general, se apoyan en sus pares, o bien en asociaciones que agrupan a estudiantes de medicina con interés científico, para satisfacer sus necesidades intelectuales.

En conjunto con lo anterior, otro gran punto que cabe mencionar corresponde al proceso de revisión del trabajo científico, pues el envío no asegura una publicación exitosa. Este proceso se lleva a cabo por un equipo editorial de la revista escogida, quienes realizan una revisión y corrección acuciosa del trabajo. Tras este procedimiento se generan, posibles, largas interacciones entre autores y revisores, disputas, frustraciones y esperas para recibir la gran noticia o la decepción de la publicación o no de su manuscrito.

Si bien éste es el último gran paso antes de ver aceptado un manuscrito, todo lo mencionado anteriormente puede generar que durante esta parte del proceso el autor sienta la necesidad de dejarlo y desechar lo andado. Este tipo de decisión suele ocurrir, sobre todo cuando las correcciones se transforman en correcciones reiteradas, sin ver el punto final.

Finalmente, es un arduo camino el publicar, no sólo por una serie de factores que están en contra de los autores, en especial quienes se inician en este camino, sino también por la dificultad de los propios procesos. Sin embargo y a pesar de todo, muchos médicos y estudiantes de pregrado logran publicar sus trabajos de investigación, lo que nos 
demuestra que ¡Es posible! No debemos desistir en nuestro anhelo por publicar, no debemos desanimarnos durante el trayecto, es un constante ir y venir, pero debemos ser optimistas si una de las vías elegidas no nos resulta, pues existen varias otras. La perseverancia y la paciencia son claves para quienes se inician en esto. ¡Ánimo!, que publicar, sí se puede.

Diego Clouet H. ${ }^{1, a}$

${ }^{1}$ Facultad de Medicina, Universidad Austral de Chile. Valdivia, Chile. ${ }^{a}$ Estudiante de Medicina.

\section{Referencias}

1. Miyahira J. La investigación formativa y la formación para la investigación en el pregrado. Rev Med Hered 2009; 20 (3): 119-22.

2. Grandi C, Der Parsehian S. La importancia de investigar y de publicar: 30 años de revista Sardá. Rev Hosp Mat Inf Ramón Sardá 2011; 30 (1): 2-3.

3. Mitru TN. La redacción médico científica. En: Aranda TE, Mitru TN, Costa AR, editores. ABC de la Redacción y Publicación Médico-Científica. 2da. Ed. Bolivia: Elite Impresiones; 2009. p. 23-6.

4. Weitz J, Silva H. Presentación versus publicación: análisis de trabajos presentados en Congresos Chilenos de Gastroenterología 1998 al 2002. Gastroenterol Latinoam 2005; 16(3): 287-92.

5. Toro L, Pereyra R, Nizama A, Fernando L, Vélez E, Galán E, et al. Publicación de los trabajos presentados a los congresos científicos de estudiantes de medicina, Perú 2002-2009: Características y factores asociados. Rev Perú Med Exp Salud Pública 2012; 29(4): 461-8.

Correspondencia a:

Diego Clouet Huerta

Carlos Anwandter \#440c. Valdivia, Chile.

Teléfono: +56974535074

E-mail: dclouet@hotmail.com 